\title{
Parametric optimization of coal desulfurization through Alkaline leaching
}

\author{
Faisal Rehman ${ }^{1}$, Syed Waqas Ahmad ${ }^{1 *}$, M. Shahzad Zafar ${ }^{1}$, Sajjad Ahmad ${ }^{2}$, \\ Muhammad Zia-Ul-Haq ${ }^{3}$ \\ ${ }^{1}$ University of Engineering and Technology (Faisalabad Campus) Lahore, Department of Chemical Engineering, Faculty \\ of Engineering, , $3.5 \mathrm{~km}$ Khurrianwala-Mukoowana Bypass Road, Faisalabad, Pakistan \\ ${ }^{2}$ University of Engineering \&Technology(Faisalabad Campus) Lahore, Department of Basic Sciences, $3.5 \mathrm{~km} \mathrm{Khurrian-}$ \\ wala-Mukoowana Bypass Road, Faisalabad, Pakistan \\ ${ }^{3}$ NFC Institute of Engineering \& Fertilizer Research, Department of Chemical Engineering, Faisalabad, Pakistan \\ "Corresponding author: e-mail: syed.waqas.ahmad@gmail.com
}

\begin{abstract}
Desulfurization of Pakistani coal has been carried out through alkaline leaching. During present experimental investigation, the effect of operating parameters like alkali concentration, time, temperature and particle size has also been analyzed, graphically represented and critically discussed. Parametric optimization of leaching process has been carried out by using response surface methodology (RSM) based on central composite design (CCD). The analysis of variance (ANOVA) was performed in order to assess the highest level interactions of variables and three way interactions were observed significant. Further, the optimum value of total sulfur removal was observed as $53 \%$ when the operatic conditions fixed at $10 \% \mathrm{~W} / \mathrm{V}, 60 \mathrm{~min}, 80^{\circ} \mathrm{C}$ and 140 mesh for alkaline concentration, leaching time, temperature and particle size, respectively.
\end{abstract}

Keywords: Desulfurization, Alkaline leaching, Response surface methodology, ANOVA, Central Composite design.

\section{INTRODUCTION}

Globally, coal has been used as a major source of power production (i.e., about 40 percent) owing to its abundance. It has been reported that coal reserves are more than that of oil and gas that will sufficient to fulfill the world's energy needs for about next two centuries ${ }^{1,2}$. Taking about Pakistan, which has approximately 186 billion ton of coal reserves out of which $97 \%$ of coal is lignite and rest is sub-bituminous. So, Pakistan is $6^{\text {th }}$ coal rich country ${ }^{3}$. The present energy crises in Pakistan have dragged the policy makers to utilize coal in power generation. Further, it is also worth noting that the high rank coal reserves have been exhausted globally ${ }^{4}$. As a consequence, it is the need of the hour to focus on the utilization of low rank coal, but the environmental regulations restrict its use. Hence, it is eminent to desulfurize or demineralize the low quality coal ${ }^{5}$. In addition, sulfur is one of the critical mineral matters that present in coal both in organic and inorganic forms. The presence of sulfur in coal can enhance its calorific value, however, it can pose serious destruction to ecological system as Sox and $\mathrm{H}_{2} \mathrm{~S}$ produced during combustion process. It is also worth noting that Sox can play a major role in global warming and acidic rain. Hence, desulfurization becomes a vital concern. Various techniques had been practiced to eradicate sulfur contents from coal with various restrictions ${ }^{6}$. For an instance, physical processes such as magnetic force separation and froth flotation are proficient to separate a part of pyretic sulfur but failed to remove organic sulfur ${ }^{6-8}$. Further, bio-desulfurization of coal with bacteria, such as T. ferrooxidans and T. thiooxidans, has proved its worth regarding elimination of sulfur. However, both microorganisms are not effective for removal of organic sulfur from coal ${ }^{9,10}$. It is, further, practically investigated and reported that bio-desulfurization is not a favorable process owing to its long residence time and less cost effectiveness ${ }^{11,}{ }^{12}$. Consequently, the eminence of chemical/leaching process has been increased manifolds due to the fact that afore- mentioned process is adequate of eradicating all types of sulfur like organic, inorganic and pyretic. Desulfurization of coal through leaching process was carried out both through mineral acids and alkalis. However, it has been reported that mineral acids adversely affect coal morphology. Consequently, the carbon chain structure can be disturbed resulting in rising oxygen and nitrogen contents of coal. Aforesaid argument can be supported through the experimental investigations reported by Wijaya and Zhang ${ }^{13}$. They leached the coal with $\mathrm{HNO}_{3}$, a mineral acid that caused to increase the relative concentration of nitrogen and oxygen. Consequently, new nitrogen base species formed upon combustion ${ }^{12}$. On the other hand, Ning and Xiuxing ${ }^{14}$ leached Chongqing Songzao based bituminous coal with caustic soda solution in a microwave reactor operating at $1000 \mathrm{~W}$. It was reported that a peculiar amount of pyretic sulfur (i.e., from $53.6 \%$ to $39.2 \%$ ) and thiophene sulfur (20.1 to $16.1 \%$ ) was found to remove, while sulfate sulfur increased from 17.3 to $34.6 \%{ }^{14}$. Further, Mezino coal was de-ashed and desulfurized using flotation followed by leaching with potassium hydroxide/methanol mixture and it was reported that the removal of approximately $82.5 \%$ and $82.34 \%$ of total sulfur and ash forming components, respectively, was observed ${ }^{6}$. Recently, Lakhra (Pakistan) coal was leached via molten caustic technique. It was found that $85 \%$ of ash and $40 \%$ of total sulfur was eliminated after treatment ${ }^{15}$. On the other hand, the effect of citric acid, as a complexing agent, in $\mathrm{H}_{2} \mathrm{SO}_{4}$ and $\mathrm{H}_{2} \mathrm{O}_{2}$ solution on pyretic sulfur was observed and it was noticed that $89 \%$ of pyretic sulfur removal at temperature of $50^{\circ} \mathrm{C}^{16}$. In contrary, electrochemical and sono-electrochemical methods were also employed as alternative treatment techniques ${ }^{\mathbf{1 0}, \mathbf{1 6}}$. Wei et a $\mathbf{l}^{\mathbf{1 0}}$ observed a maximum sulfur removal of $65 \%$ when they electrolyzed a sample of Chinese coal by applying $10 \mathrm{~V}$ DC potential for 20 minutes followed by flotation technique ${ }^{10}$. In another experimental study, sono-electrochemical technique was used to reduce the total sulfur contents of Chinese coal. 
It has been reported that total sulfur reduction was $75.4 \%$ when sono-electrolyze parameters were kept at $20 \mathrm{~min}$, $15 \times 10^{-3} \mathrm{~A} / \mathrm{cm}^{2}, 2.1 \mathrm{~mol} / \mathrm{L}$ and $1.2 \mathrm{~W} / \mathrm{cm} 2$ for resident time, current density, concentration of anhydrous ethanol and ultrasound density respectively ${ }^{16}$. Despite of the significant sulfur removal through aforementioned technique (i.e. electrochemical and sono-electrochemical), the hydrophobicity of resultant coal weakens on the surface owing to oxidation. Consequently, the eradication of sulfur from interior coal particle can be difficult. It can be deduced from the discussion of the preceding section that sulfur removal from coal is eminent before oxidation. Further, acidic leaching, electrochemical and sono-electrochemical techniques can destroy the basic coal structure. Consequently, alkali leaching technique was selected for contemporary investigations in sulfur removal process of Pakistani coal collected from Chakwal district. RSM is a mathematical and statistical approach to improve and optimize the process variables for method development. Recently it has found important applications in formulation of new products and biochemical processes ${ }^{17}$. In this work, parametric effect of leaching process has been determined and optimized through response surface methodology (RSM) technique.

\section{MATERIAL AND METHODOLOGY}

\section{Materials and Characterization}

The raw coal, bituminous grade, was collected from ChoaSaidan Shah (District Chakwal), Pakistan. Lab grade chemicals like; sodium hydroxide $(\mathrm{NaOH})$, barium chloride $\left(\mathrm{BaCl}_{2}\right)$ and hydrochloric acid $(\mathrm{HCl})$ were purchased from Merck Germany. Distilled water was prepared in a lab scale distillation unit. The Proximate analysis of coal was carried out to estimate moisture and ash contents, volatile matter and fixed carbon in accordance to the ASTM standards D-3173-75. Further, ESCHKA method (ASTM D-3177) was performed to approximate total sulfur contents in coal, see Table 1.

\section{Experimentation}

The required particle size of coal, i.e. 60, 100 and 140 mesh, was achieved by crushing, grinding and screening in sequence. Afterwards, 30 grams of crushed sample was treated with $200 \mathrm{ml}$ of 5 and $10 \% \mathrm{~W} / \mathrm{V} \mathrm{NaOH}$ solution. To optimize the operating conditions, the experimental scheme was developed based on central composite design (CCD) of response surface methodology (RSM). A three-level CCD, consisting of three continuous factors (i.e. time, temperature, particle size) and one categorical factor (i.e. solvent $(\mathrm{NaOH})$ concentration with two levels), was developed, see Table 2 for further details. It is also worth noting that the stirring rate was kept constant at 500 RPM throughout the experimental investigations. The treated sample of coal was filtered through what-man filter paper \# 42. The filtrate was, then, washed with double distilled water to get rid of process contaminations. Afterwards, the filtered coal was dried in an electric oven at $105^{\circ} \mathrm{C}$ for 2 hours. Finally, moisture and total sulfur contents were estimated and the process performance was evaluated using Equation 1. The schematic experimental steps have been portrayed in Figure 1.

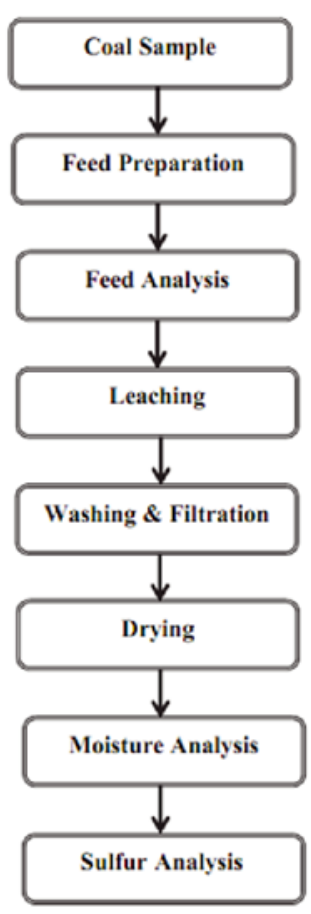

Figure 1. The schematic diagram of experimental procedure

$\alpha=\left[\frac{X_{1}-X_{2}}{X_{1}}\right] \times 100$

Where; $\alpha=$ percentage reduction in sulfur, $X_{1}=$ sulfur percentage in coal sample before leaching, $X_{2}=$ sulfur percentage in coal sample after leaching.

Based on central composite design (CCD), the percentage eradication of sulfur is the function of time, temperature, particle size and solvent concentration. It can be described mathematically as follows:

$\mathrm{R}=f(\mathrm{~A}, \mathrm{~B}, \mathrm{C}, \mathrm{D})$

Table 1. Proximate analysis of raw coal

\begin{tabular}{|l|c|c|c|c|}
\hline & Moisture [\%] & Volatile Matter [\%] & Ash [\%] & Fixed carbon [\%] \\
\hline Air Dried & 0.262 & 34.5975 & 36.3327 & 28.8078 \\
\hline Dried & - & 34.6883 & 36.4281 & 5.03 \\
\hline
\end{tabular}

Table 2. Experimental scheme of process variables for response surface methodology (RSM) based on central composite design (CCD)

\begin{tabular}{|c|c|c|c|c|}
\hline \multirow[t]{3}{*}{ Level } & \multicolumn{4}{|c|}{ Parameters } \\
\hline & \multicolumn{3}{|c|}{ Continuous Factors } & Categorical Factor \\
\hline & Time [min] & Temperature $\left[{ }^{\circ} \mathrm{C}\right]$ & Particle Size [mesh] & $\mathrm{NaOH}$ Concentration $[\% \mathrm{w} / \mathrm{v}]$ \\
\hline 1 & 20 & 40 & 60 & 5 \\
\hline 3 & 60 & 80 & 140 & \\
\hline
\end{tabular}


Where; $\mathrm{R}$ is the response showing the percentage removal of total sulfur from coal, $f$ is the response function and variables are $\mathrm{A}, \mathrm{B}, \mathrm{C}$ and $\mathrm{D}$ are time, temperature, particle size and solvent concentration, respectively.

\section{Statistical analysis}

\section{Model Fitting and summary statistics}

Based on model statistical summary of CCD (see Table 3), the polynomial model with highest order was selected where model was not aliased. Moreover, the insignificant lack of fit was achieved by focusing on maximizing the values of adjusted and predicted R-squared. So, the quadratic model was suggested for sulfur removal from coal. Further, the "Prob $>$ F" value for the 2FI vs Linear model was much higher $(0.0259)$ than the Quadratic vs 2FI model $(<0.0001)$. The significant model terms (for $95 \%$ confidence intervals) with $\mathrm{p}$ values were less than 0.05. So, statistical 'Model Fit Summary' ascertained the suitability of the quadratic model compared to two factor interaction $(2 \mathrm{FI})$ model as the sequential $\mathrm{p}$-value for quadratic model is $<0.0001$ than that of others. In experimental design, $\mathrm{R}^{2}$ is an estimate of amount of variation around the mean described by the model. The predicted value of R-squared (i.e. 0.8467), for the quadratic model, is found in reasonable agreement with the adjusted value of R-squared (i.e. 0.9454). The resultant quadratic model in terms of coded variables can be presented, mathematically, in Equation (3) and (4) for $5 \%$ and $10 \%$ solvent concentration, respectively. $\mathrm{R}=-55.7607+0.9295 \mathrm{~A}+1.0664 \mathrm{~B}+0.3238 \mathrm{C}-1.5125$ x $10^{-3} \mathrm{AB}-7.7812$ x $10-4 \mathrm{AC}-1.6968 \times 10^{-3} \mathrm{BC}-4.6079$ x $10^{-3} \mathrm{~A}^{2}-4.2829 \times 10^{-3} \mathrm{~B}^{2}-1.7698 \times 10^{-3} \mathrm{C}^{2}$

$\mathrm{R}=-83.18172+2.06819 \mathrm{~A}+1.74408 \mathrm{~B}+0.27560 \mathrm{C}-$ $9.1781 \times 10^{-3} \mathrm{AB}-3.3984 \times 10^{-3} \mathrm{AC}-2.7046 \times 10^{-3} \mathrm{BC}-$ $1.0281 \times 10^{-2} \mathrm{~A}^{2}-6.3806 \times 10^{-3} \mathrm{~B}^{2}+6.0483 \times 10^{-4} \mathrm{C}^{2}$

Where $\mathrm{R}$ is the percentage sulfur removal, $\mathrm{A}$ is the contact time in minutes, $\mathrm{B}$ is the leaching temperature in ${ }^{\circ} \mathrm{C}$ and $\mathrm{C}$ is the particle size of coal in mesh.

\section{ANOVA}

Analysis of variance (ANOVA) for quadratic model response, the percentage sulfur removal, was used to justify the adequacy of the model. The model provided the accurate description of the experimental data indicating successful correlation among four independent variables that effect the sulfur removal from coal. The ANOVA is summarized in Table 4. An effect was considered to be significant if its significance level was greater than 95\%. Further, the P-value smaller than 0.05 implies that corresponding model term is significant. The highest calculated value of $\mathrm{F}$ and lowest value of $\mathrm{P}$ model can be considered as significant for the response of sulfur removal. The contribution and significance of each process variables and their interaction was evaluated. On the basis of $F$ values (see Table 4), it can be deduced that time is the most important parameter for sulfur removal process from coal followed by temperature and particle size. In case of process parameter interactions, only high level interactions are considered. As a consequence, $\mathrm{ABD}$ has the highest $\mathrm{F}$ factor value, i.e. 10.48, and considered as the most significant combination of process parameters. Moreover, the signs of the linear terms of Equation (3) and (4) are positive indicating the physical significance of all process variables during the removal of sulfur from coal.

\section{Normal Plots of Residual}

In statistics, a studentized residual is the proportion resulting from the division of a residual by an estimate of its standard deviation Residuals are the differences amongst predicted and actual values for every point and reveals how well the predicted model satisfies the presumptions of ANOVA. The plots represented in Figures 2 and 3 depict the strong agreement between the values of predicted and actual response and validate the model accuracy. The normal distribution of residuals depicts the adequacy of the statistical model. Further, the percentage sulfur removal experimentally determined is correlated to predicted values. Pearson correlation is used to reveal the correlation between experimental and predicted values by statistical model. Statistical analysis indicates a high positive value of Pearson correlation

Table 3. Statistical summary of CCD for Response R

\begin{tabular}{|c|c|c|c|c|c|c|}
\hline Source & Sum of Squares & Df & $\begin{array}{l}\text { Mean } \\
\text { Square }\end{array}$ & $\begin{array}{c}\mathrm{F} \\
\text { Value }\end{array}$ & $\begin{array}{l}\text { p-value } \\
\text { Prob }>\text { F }\end{array}$ & \\
\hline Mean vs Total & 60943.00 & 1 & 60943.00 & & & \\
\hline Linear vs Mean & 3376.78 & 4 & 844.19 & 55.78 & $<0.0001$ & \\
\hline Quadratic vs 2FI & 190.54 & 3 & 63.51 & 11.62 & $<0.0001$ & Suggested \\
\hline Cubic vs Quadratic & 116.55 & 10 & 11.65 & 7.28 & 0.0003 & Aliased \\
\hline Residual & 25.61 & 16 & 1.60 & & & \\
\hline Total & 64849.45 & 40 & 1621.24 & & & \\
\hline \multicolumn{7}{|c|}{ Lack of Fit Tests } \\
\hline Linear & 523.71 & 25 & 20.95 & 35.19 & $<0.0001$ & \\
\hline $2 \mathrm{FI}$ & 326.75 & 19 & 17.20 & 28.89 & $<0.0001$ & \\
\hline Quadratic & 136.20 & 16 & 8.51 & 14.30 & $<0.0001$ & Suggested \\
\hline Cubic & 19.66 & 6 & 3.28 & 5.50 & 0.0093 & Aliased \\
\hline Pure Error & 5.95 & 10 & 0.60 & & & \\
\hline \multicolumn{7}{|c|}{ Model Summary Statistics } \\
\hline Source & Std. Dev. & R-Squared & $\begin{array}{c}\text { Adjusted } \\
\text { R-Squared }\end{array}$ & $\begin{array}{c}\text { Predicted } \\
\text { R-Squared }\end{array}$ & PRESS & \\
\hline Linear & 3.89 & 0.8644 & 0.8489 & 0.8041 & 765.45 & \\
\hline $2 \mathrm{FI}$ & 3.39 & 0.9148 & 0.8855 & 0.7302 & 1053.95 & \\
\hline Quadratic & 2.34 & 0.9636 & 0.9454 & 0.8467 & 598.92 & Suggested \\
\hline Cubic & 1.27 & 0.9934 & 0.9840 & 0.8164 & 717.40 & Aliased \\
\hline
\end{tabular}


Table 4. Analysis of variance (ANOVA) results for sulfur removal from coal

\begin{tabular}{|c|c|c|c|c|c|c|}
\hline Source & Sum of Squares & Df & Mean Square & F Value & $\begin{array}{l}\text { p-value } \\
\text { Prob }>F\end{array}$ & \\
\hline Model & 3834.66 & 19 & 201.82 & 56.23 & $<0.0001$ & significant \\
\hline A-Time & 1117.51 & 1 & 1117.51 & 311.37 & $<0.0001$ & \\
\hline B-Temperature & 879.40 & 1 & 879.40 & 245.02 & $<0.0001$ & \\
\hline C-Particle size & 515.52 & 1 & 515.52 & 143.64 & $<0.0001$ & \\
\hline $\mathrm{D}-\mathrm{NaOH}$ concentration & 442.38 & 1 & 442.38 & 123.26 & $<0.0001$ & \\
\hline$A B$ & 73.15 & 1 & 73.15 & 20.38 & 0.0002 & \\
\hline$A C$ & 44.66 & 1 & 44.66 & 12.44 & 0.0021 & \\
\hline AD & 2.75 & 1 & 2.75 & 0.77 & 0.3915 & \\
\hline $\mathrm{BC}$ & 49.60 & 1 & 49.60 & 13.82 & 0.0014 & \\
\hline $\mathrm{BD}$ & 0.68 & 1 & 0.68 & 0.19 & 0.6670 & \\
\hline$C D$ & 26.13 & 1 & 26.13 & 7.28 & 0.0138 & \\
\hline$A^{2}$ & 48.77 & 1 & 48.77 & 13.59 & 0.0015 & \\
\hline $\mathrm{B}^{2}$ & 25.02 & 1 & 25.02 & 6.97 & 0.0157 & \\
\hline $\mathrm{C}^{2}$ & 0.64 & 1 & 0.64 & 0.18 & 0.6763 & \\
\hline ABD & 37.61 & 1 & 37.61 & 10.48 & 0.0041 & \\
\hline ACD & 17.58 & 1 & 17.58 & 4.90 & 0.0387 & \\
\hline BCD & 2.60 & 1 & 2.60 & 0.72 & 0.4048 & \\
\hline$A^{2} D$ & 7.08 & 1 & 7.08 & 1.97 & 0.1755 & \\
\hline$B^{2} D$ & 0.97 & 1 & 0.97 & 0.27 & 0.6092 & \\
\hline$C^{2} D$ & 2.15 & 1 & 2.15 & 0.60 & 0.4478 & \\
\hline Residual & 71.78 & 20 & 3.59 & & & \\
\hline Lack of Fit & 65.83 & 10 & 6.58 & 11.06 & 0.0004 & significant \\
\hline Pure Error & 5.95 & 10 & 0.60 & & & \\
\hline Cor Total & 3906.44 & 39 & & & & \\
\hline
\end{tabular}

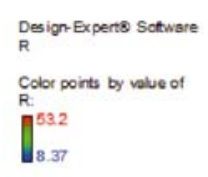

Figure 2. Normal plot of residuals
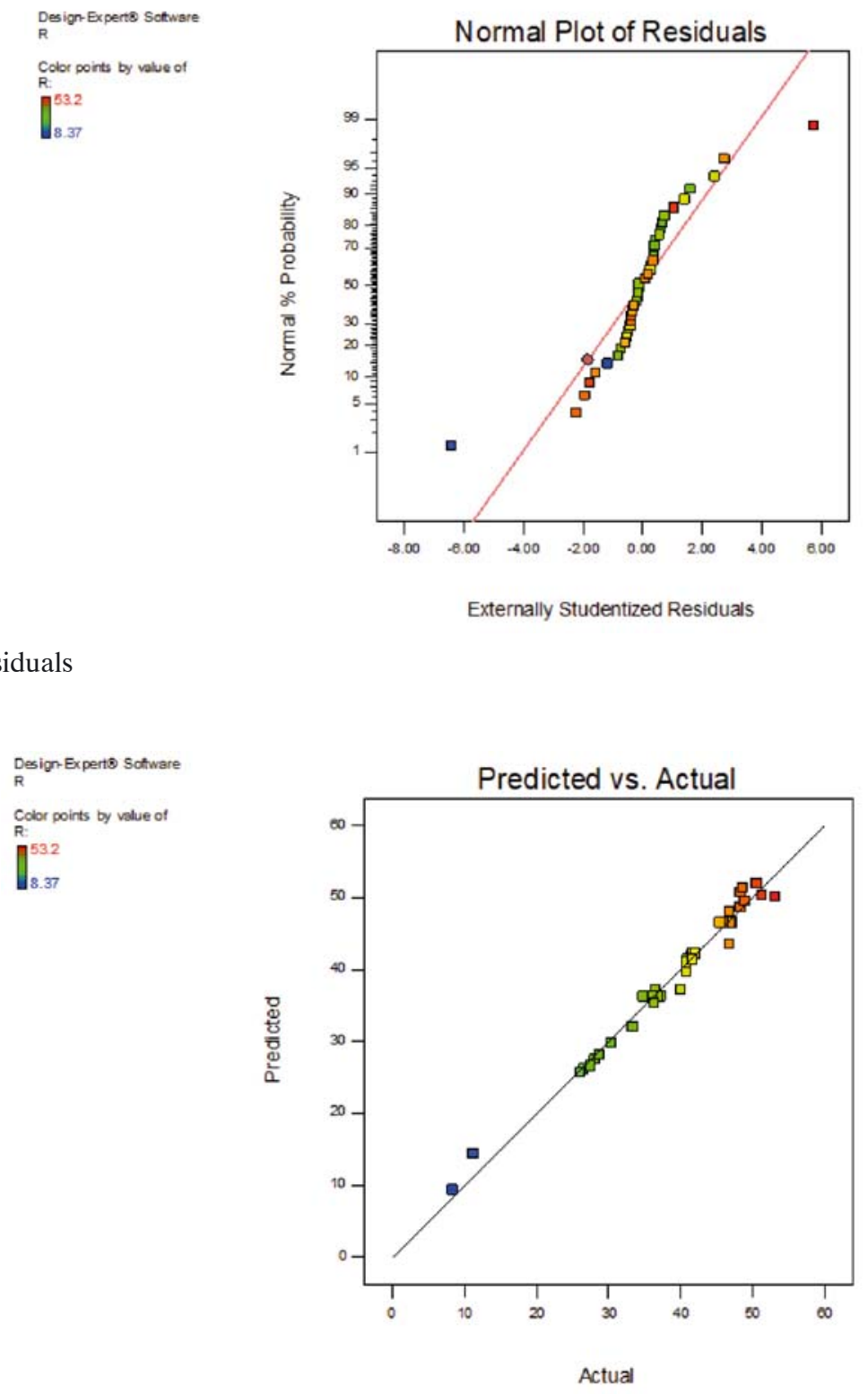

Figure 3. Predict vs actual plot for percentage sulfur removal 
coefficient (i.e. 0.98164), that was mathematically calculated through Equation (5)

$$
P=\frac{\sum x y-\frac{\sum x \sum y}{n}}{\sqrt{\left(\sum x^{2}-\frac{(\Sigma x)^{2}}{n}\right)-\left(\sum y^{2}-\frac{(\Sigma y)^{2}}{n}\right)}}
$$

Where; $\mathrm{P}$ is Pearson correlation coefficient, $\mathrm{x}$ is experimentally determined percentage sulfur removal and $y$ is predicted values and $\mathrm{n}$ is the number of experiments.

\section{Response surface plots}

The contour plots and 3D response surface plots of the model depict the effect of interaction of process variables. The function of the contour plots is to show the change in response with the change in two process parameters. Since the model has one response and more than two parameters therefore several contour plots and 3D plots were created. Each aforesaid plot targeted two independent variables while keeping the remaining parameters constant.

\section{RESULTS AND DISCUSSIONS}

The four process parameters, having three continuous factors of time $(\mathrm{min})$, temperature $\left({ }^{\circ} \mathrm{C}\right)$ and particle size (mesh) and one categorical factor of solvent concentration $(\% \mathrm{~W} / \mathrm{V})$ were studied for sulfur removal from coal using CCD. The regression analysis for response (percentage sulfur removal) was performed using Design Expert software version 10.0. The results are discussed, statistically elucidated and graphically elaborated in the subsequent section.

\section{Effect of time and temperature}

The leaching time and temperature was varied from $20-60$ minute and $40-80^{\circ} \mathrm{C}$ respectively and the response behavior of interactions of both these parameters can be well explained through Figures 4 (a) \& (b). It can be deduced that as the leaching time and temperature increased the percentage removal from coal also increases from 33.4 to $53.2 \%$ while keeping other parameters constant. It can be explained on the fact that as dealing time increases the probability of successful collisions between the solvent and the coal particles increases and more sulfur content dissolve in the solution. The rise in sulfur removal rises as temperature increased it may be due to that the temperature enhances the reaction rate between sodium hydroxide and sulfur content and also due to the increase in mass transfer rate. The contact time has the highest F-value and positive impact on percentage sulfur removal from coal that can be observed from Table 4. The increasing value of sulfur removal with increasing time and temperature was also observed when Makum coal was leached with $\mathrm{KOH}^{18}$.

\section{Effect of time and particle size}

The coal particle size varies from 60 to 140 mesh along with variation in leaching time and the response behavior has been illustrated in Figures 5(a) \& (b). It is evident that by decreasing the particle size or by increasing the mesh number along with increase in leaching time, the percentage removal of sulfur content increased from 40.91 to $53.2 \%$, keeping all other parameters constant. The reason lies in the increase in surface area between the solvent and the leachable content on decreasing particle size due to which mass transfer rate between solvent and sulfur content increases and hence more sulfur dissolve in solution. The maximum sulfur removal was achieved at the particle size of 140 mesh reaching up to $53.2 \%$. The similar results were reported when Indian coal was leached with alkali having different particle sizes ${ }^{19}$.

\section{Effect of Particle Size and Temperature}

It can be observed from Figures 6(a) and 6(b) that the increase in mesh number along with leaching temperature dissolve more sulfur from coal into the solution and the total sulfur content decreased from 41.61 to $53.2 \%$ from coal by keeping other two parameters constant. The increase in temperature along with increasing particle surface area enhances the reaction rate between sodium hydroxide and different forms of sulfur present in coal.

\section{Effect of $\mathrm{NaOH}$ concentration}

Sodium hydroxide was very efficient for eliminating all forms of sulfur (organic and inorganic) present in coal. Sodium hydroxide increases the desulfurization rate at higher concentrations because the more alkali available to react with both organic and inorganic sulfur in coal. It can be deduced from the reactions between alkali and coal that the hydrogen atom in alkali can play a vital role in breaking $\mathrm{C}-\mathrm{S}$ bonds and sulfur eradication ${ }^{20}$.
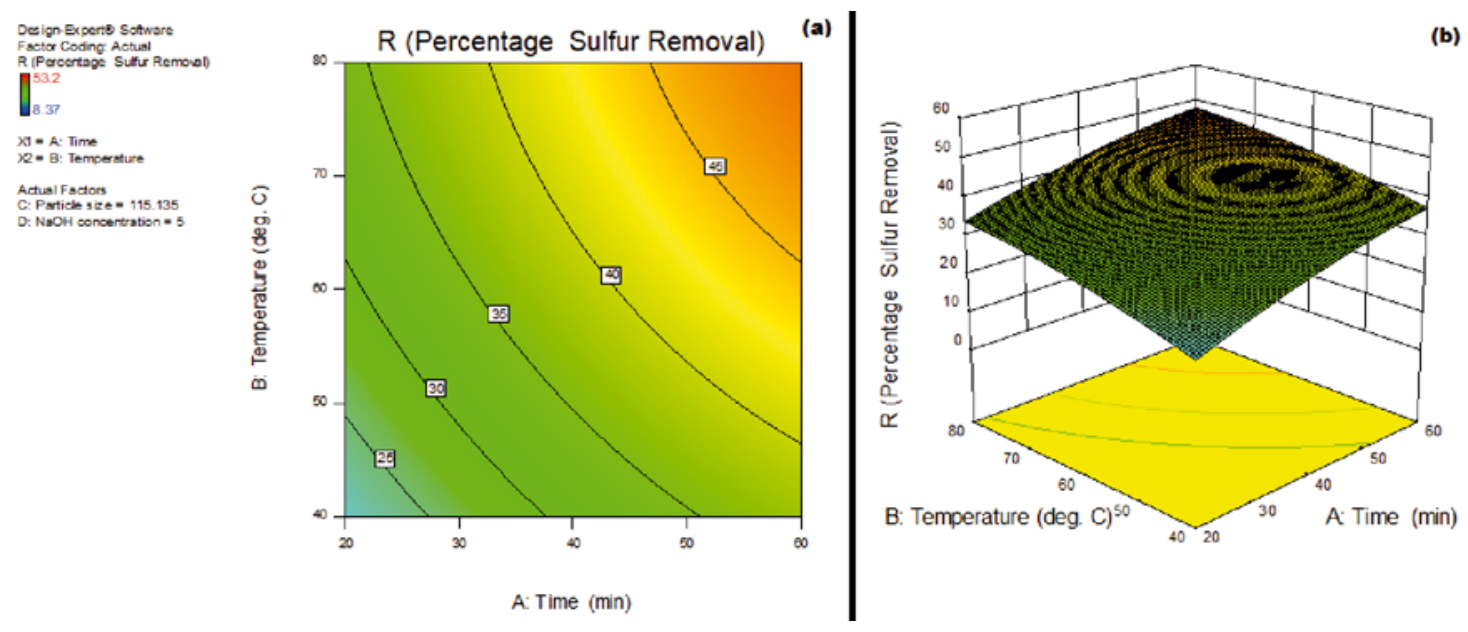

Figure 4. Effect of time and temperature on percentage sulfur removal (a) contour plot (b) surface plot 


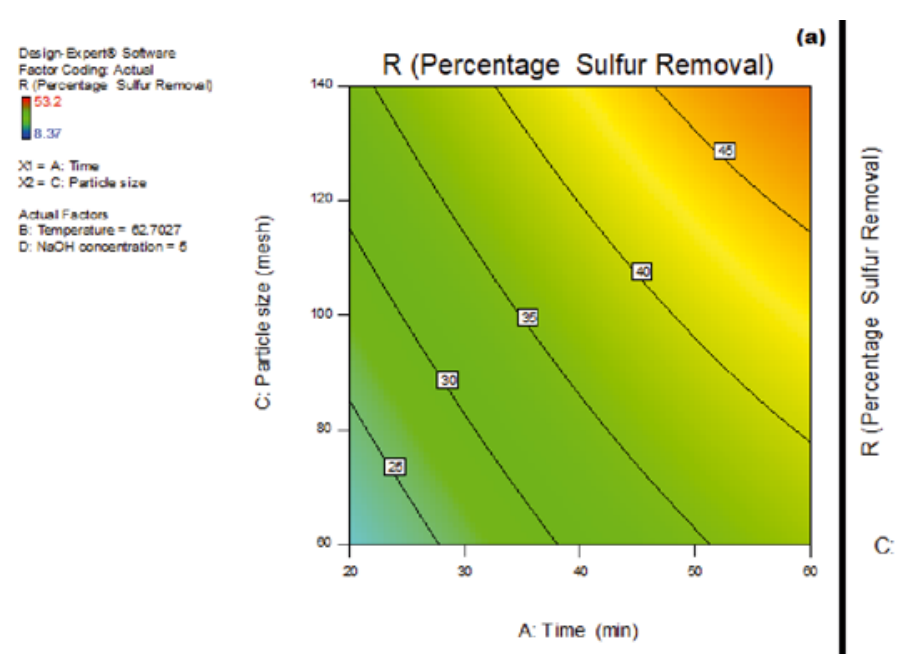

(b)

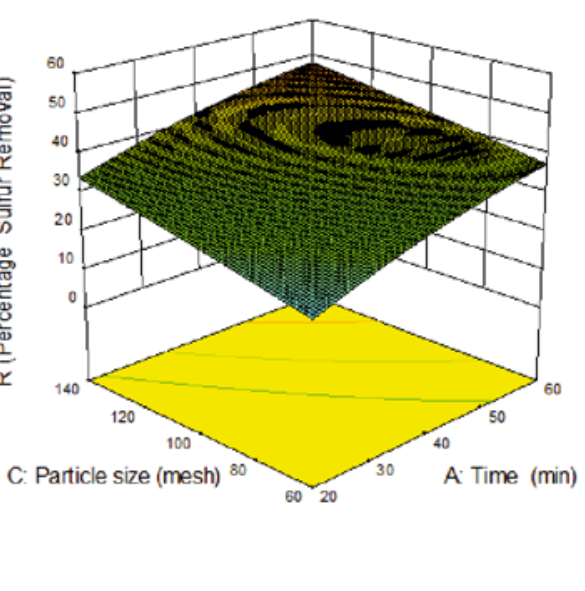

Figure 5. Effect of time and particle size on percentage sulfur removal (a) contour plot (b) surface plot

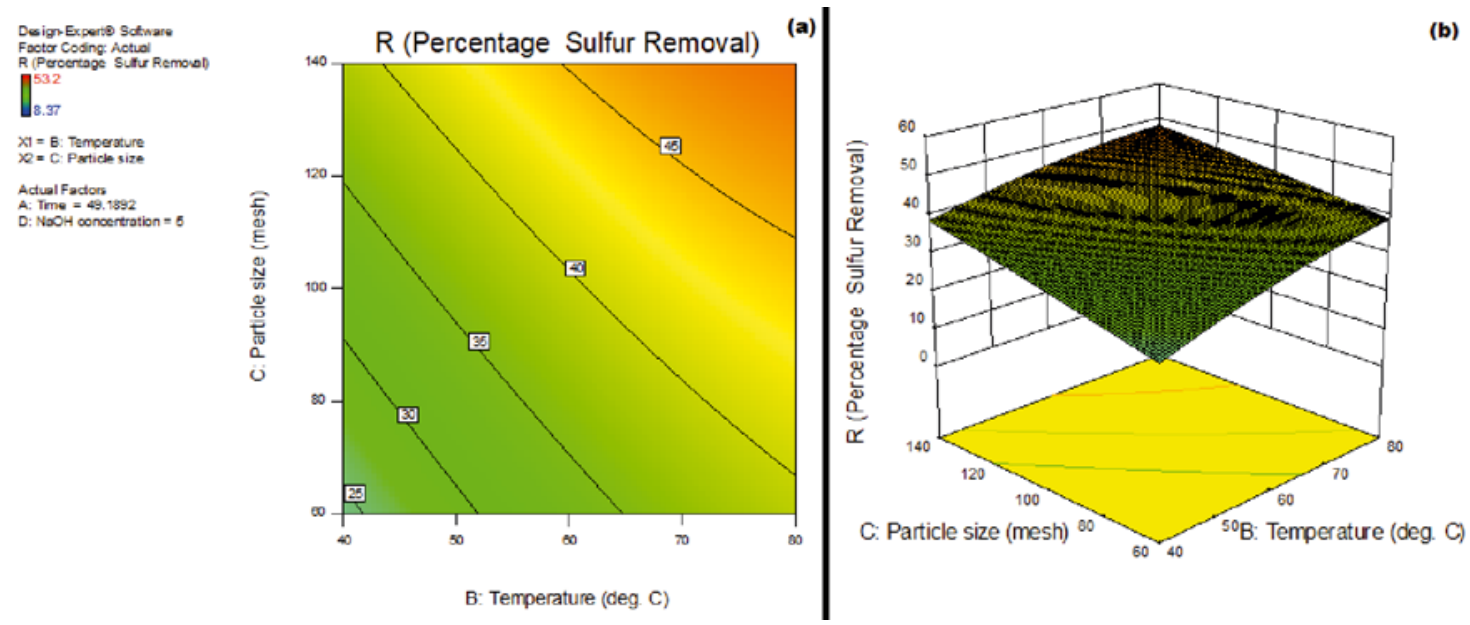

Figure 6. Effect of temperature and particle size on percentage sulfur removal (a) contour plot (b) surface plot

\section{Optimization of leaching parameters}

After the development and validation of process model, the optimization of the extraction variables was carried out using Design Expert software version 10.0 numerical optimization tool. The purpose of optimization was to maximize the response function, i.e. the percentage sulfur removal, within the lower and upper limits of $8.37 \%$ and $53.2 \%$. Numerical optimization was used to find a set of process variables that can give the maximum value of the response function at highest desirability. The optimum values of the process parameters were found as time 43.23 minutes, temperature $78.78^{\circ} \mathrm{C}$, particle size 136.64 mesh and alkali concentration $10 \% \mathrm{~W} / \mathrm{V}$ with the predicted sulfur removal of $50.84 \%$ at 1 desirability.

\section{CONCLUSIONS}

Coal desulfurization was carried out using alkali leaching technique. The sodium hydroxide was utilized as a solvent and the parametric optimization was performed for desulfurization process. The leaching parameters like contact time (A), temperature (B), coal particle size (C) and sodium hydroxide concentration (D) were optimized using response surface methodology (RSM) under central composite design (CCD). For optimization, a quadratic model was developed and validated. Analysis of variance (ANOVA) was performed, which indicates that contact time is the prime parameter that effect the percentage sulfur removal from coal, further, temperature, coal particle size and solvent concentration were also found significant. Additionally, it was observed that the maximum sulfur removal, i.e. $50.84 \%$ with ' 1 ' desirability, was determined when time, temperature, particle size and solvent concentration were at $43.23 \mathrm{~min}, 78.78^{\circ} \mathrm{C}$, 136 mesh and $10 \% \mathrm{~W} / \mathrm{V}$, respectively.

\section{LITERATURE CITED}

1. Xia, W., Xie, G. \& Peng, Y. (2015) Recent advances in beneficiation for low rank coals. Powder Technol. 277, 206. DOI: 10.1016/j.powtec.2015.03.003 10.1016/j.powtec.2015.03.003.

2. Demirbas, M. (2007) Progress of fossil fuel science. Energ. Source Part. B. 2(3), 243. DOI: 10.1080/15567240500402909 $10.1080 / 15567240500402909$.

3. Malkani, M.S. (2012) A review of coal and water resources of Pakistan. J. Sci. Technol. Dev. 31(3), 202.

4. Shen, S., He, J., Pan, M., Zhou, Z., Feng, C. \& Liang, G. (2012) Effective removal of sulfur from high-sulfur coal prior to use by dry chlorination at low temperature. J. Hazard. Mater. 217-218, 116. DOI: 10.1016/j.jhazmat.2012.03.001 https://doi. org/10.1016/j.jhazmat.2012.03.001.

5. Ge, L., Zhang, Y., Wang, Z., Zhou, J. \& Cen, K. (2013) Effects of microwave irradiation treatment on physicochemical characteristics of Chinese low-rank coals. Energ. Convers. Manage 71, 84. DOI: 10.1016/j.enconman.2013.03.021 10.1016/j. enconman.2013.03.021.

6. Abdollahy, M., Moghaddam, A. \& Rami, K. (2006) Desulfurization of mezino coal using combination of 'flotation'and 'leaching with potassium hydroxide/methanol. Fuel 85(7), 1117. DOI: 10.1016/j.fuel.2005.10.011 10.1016/j.fuel.2005.10.011. 
7. Demirbaş, A. (2002) Demineralization and desulfurization of coals via column froth flotation and different methods. Energy Convers Manage 43(7), 885. DOI: 10.1016/S0196-8904(01)000887 10.1016/S0196-8904(01)00088-7.

8. Celik, M. \& Yildirim, I. (2000) A new physical process for desulfurization of low-rank coals. Fuel 79(13), 1665. DOI: 10.1016/S0016-2361(00)00013-2 10.1016/S0016-2361(00)00013-2.

9. He, H., Hong, F.F., Tao, X.X., Li, L., Ma, C.Y. \& Zhao, Y.D. (2012) Biodesulfurization of coal with Acidithiobacillus caldus and analysis of the interfacial interaction between cells and pyrite. Fuel Process. Technol. 101, 73. DOI: 10.1016/j.enconman.2013.03.021 10.1016/j.enconman.2013.03.021.

10. Ivanov, I. (2007) Main trends in the biotechnological processing of coals: a review. Solid Fuel Chem. 41(1), 3. DOI: $10.3103 / \mathrm{S} 036152190701002810.3103 / \mathrm{S} 0361521907010028$.

11. Wei, Z., Xu, W.J., Zhong, S.T. \& Zong, Z.M. (2008) Desulfurization of coal by an electrochemical-reduction flotation technique. J. China Univ. Min. Technol. 18(4), 571. DOI: 10.1016/S1006-1266(08)60296-5 10.1016/S1006-1266(08)60296-5.

12. Meshram, P., Purohit, B.K., Sinha, M.K., Sahu, S. \& Pandey, B. (2015) Demineralization of low grade coal-A review. Renewable and Sustainable Energy Reviews 41, 745.

13. Wijaya, N. \& Zhang, L. (2011) A critical review of coal demineralization and its implication on understanding the speciation of organically bound metals and submicrometer mineral grains in coal. Energy Fuel 25(1), 1. DOI: 10.1021/ ef1008192 10.1021/ef1008192.

14. Ning, X. \& Xiuxiang, T. (2015) Changes in sulfur form during coal desulfurization with microwave: Effect on coal properties. International J. 3, 016.

15. Wahab, A., Nawaz, S., Shahzad, K., Akhtar, J., Kanwal, S., Munir, S. \& Sheikh, N. (2015) Desulfurization and demineralization of Lakhra coal by molten caustic leaching. Energy Sources Part A 37(11), 1219. 10.1080/15567036.2013.837547 10.1080/15567036.2013.837547.

16. Pecina, E., Rendón, N., Dávalos, A., Carrillo, F. \& Martínez, D. (2014) Evaluation of Process Parameters of Coal Desulfurization in Presence of $\mathrm{H} 2 \mathrm{O} 2$ and Complexing Agents. Int. J. Coal Prep. Util. 34(2), 85. DOI: 10.1016/S00162361(02)00360-5 10.1016/S0016-2361(02)00360-5.

17. Baş, D. \& Boyac1, I.H. (2007) Modeling and optimization I: Usability of response surface methodology. J. Food Engineer. 78(3), 836. https://doi.org/10.1016/j.jfoodeng.2005.11.024 https:// doi.org/10.1016/j.jfoodeng.2005.11.024

18. Mukherjee, S. \& Borthakur, P.C. (2003) Effect of leaching high sulphur subbituminous coal by potassium hydroxide and acid on removal of mineral matter and sulphur. Fuel 82(7), 783. DOI: 10.1016/S0016-2361(02)00360-5 10.1016/S00162361(02)00360-5.

19. Baruah, B. \& Khare, P. (2007) Desulfurization of oxidized Indian coals with solvent extraction and alkali treatment. Energy Fuel 21(4), 2156. DOI: 10.1021/ef070087a 10.1021/ef070087a.

20. Liu, K., Yang, J., Jia, J. \& Wang, Y. (2008) Desulphurization of coal via low temperature atmospheric alkaline oxidation. Chemosphere 71(1), 183. DOI: 10.1016/j.chemosphere.2007.10.005 10.1016/j.chemosphere.2007.10.005. 